\title{
Isolation, characterization and symbiotic performance evaluation of soybean (Glycine max) nodulating rhizobia from different districts of Bangladesh
}

\author{
Syed Raju Ali', Mohammad Habibur Rahman', Shefali Khatun', Sabina Yasmin ${ }^{1}$ and Md. \\ Harun-or Rashid ${ }^{*}$
}

\author{
1Department of Biotechnology, Bangladesh Agricultural University, Mymensingh-2202, Bangladesh. \\ 2Biotechnology Division, Bangladesh Institute of Nuclear Agriculture, Mymensingh-2202, Bangladesh.
}

*Corresponding author. Email: mhrashid08@gmail.com

\begin{abstract}
Copyright (c) 2019 Sattar et al. This article remains permanently open access under the terms of the Creative Commons Attribution License 4.0, which permits unrestricted use, distribution, and reproduction in any medium, provided the original work is properly cited.
\end{abstract}

Received 4th December, 2018; Accepted 18th January, 2019

\begin{abstract}
Rhizobia can meet up nitrogen requirement of legumes by biological nitrogen fixation through symbiosis. The main objective of this study was to find out the morpho-physiological diversity of indigenous soybean nodulating rhizobia and to find effective rhizobial strains for enhancing better soybean production at different environmental conditions. Fourteen rhizobial strains were isolated and studied their morph-physiological characteristics; evaluated their nodulation and symbiotic efficiency at potted soil. Among the strains, seven were slow growing, four were intermediate to slow growing and three were fast growing. The strains exposed creamy, milky-white and transparent single colonies between 1.17 and $3.67 \mathrm{~mm}$ in diameter after 3 to 7 days on growth medium. Twelve strains were alkali producers and only two strains were acid producers. Most of them tolerated both acidic $\mathrm{pH}(4.0$ and 5.0) and alkaline $\mathrm{pH}(9.0$ and 10.0) conditions. All strains tolerated to $1.0 \% \mathrm{NaCl}$ but none of them survived at $5.0 \%$ salt stress. They retained their normal growth up to $37^{\circ} \mathrm{C}$ but most of them showed growth susceptibility at $45^{\circ} \mathrm{C}$ and growth was inhibited at $50^{\circ} \mathrm{C}$. The strains were inoculated as treatments on soybean plants to compare their performance on growth of soybean along with urea and control treatment. Overall, rhizobial treatments significantly increased nodulation and growth of soybean plants over recommended dose of urea and negative control. Diverse rhizobial strains were associated with soybean root nodules in Bangladesh. The strains SB-27, SB-28 and SB-212 were very effective and produced almost double plant dry matter weight over some other strains, dose of urea and negative control. The physical stress tolerant and highly symbiotic strains deserve to be effective as bio-fertilizer for soybean crop production.
\end{abstract}

Keywords: Bio-fertilizer, biological nitrogen fixation, nodulation, rhizobia, symbiosis.

\section{INTRODUCTION}

Rhizobia are gram negative, non-pathogenic and beneficial soil bacteria. The name rhizobia firstly coined by Frank in 1889, as they form nodules on the root and stem of leguminous plants (Jordan, 1984). More than 98 species of rhizobia have been identified, belonging to 14 genera of $\alpha$ and $\beta$-proteobacteria (Berrada and Fikri-Benbrahim, 2014). Rhizobia enriched their value due to some highly important genes which are responsible for nodulation and biological nitrogen fixation (MacLean et al., 2007). Through a symbiotic relationship, rhizobia fix free atmospheric nitrogen into the usable forms of nitrogenous compounds and supply to the host legume, and the bacteria become benefited by consuming their required carbon sources and other nutrients from the host plants (McNeill and Unkovich, 2007). The plant soybean (Glycine max L.) is the world's foremost oil producing legume crop, 
deserved the seventh position among world crops by tonnage harvested (Ross-Ibarra et al., 2007). It represents $50 \%$ of the global legume crop area and $68 \%$ of global legume production (Herridge et al., 2008), having a symbiotic relationship with rhizobia. The plants cannot fix free nitrogen from the environment by their own mechanisms but nitrogen is an integral part of many plants like soybean for making its essential amino acids and other nutrients of the plant (Goormachtig et al., 2004).

Nitrogen fertilization is not only extremely expensive but also contaminates environments such as groundwater by leaching and emission of atmospheric greenhouse gases that contribute to global warming. The screening of rhizobia adapted to local conditions and searching for highly effective strains for use as inoculants represents a promising strategy in overcoming inoculation failure (Chibeba et al., 2017). The efficient rhizobial strains can be used as bio-fertilizer which bears higher efficiency over the chemical nitrogenous fertilizers and contributes to the sustainable agriculture (Anwar, 2010). The main objective of this study was to find out the morpho-physiological diversity of indigenous soybean nodulating rhizobia and to find effective rhizobial strains which can facilitate soybean for better production at different environmental conditions.

\section{MATERIALS AND METHODS}

\section{Nodule collection}

The soybean root nodules were collected from ChapaiNawabganj, Lakshmipur, Mymensingh and Noakhali districts of Bangladesh (Figure 1). The fresh, intact and pinkish nodules were collected carefully from field grown healthy soybean plants. Then, the nodules were washed with tap water and dried at room temperature. Later, the nodules were preserved in falcon tubes with silica gel.

\section{Isolation of rhizobia from nodules and their preservation}

The juvenile and intact nodules were surface sterilized, firstly with $70 \%(\mathrm{v} / \mathrm{v})$ ethanol for 45 seconds; secondly with $1 \%(\mathrm{v} / \mathrm{v})$ sodium hypochlorite $(\mathrm{NaOCl})$ for three minutes, and then nodules were rinsed with distilled water for at least six times perfectly to remove surface disinfectant. The surface sterilized nodules were then crushed in distilled water $(50 \mu \mathrm{L} /$ nodule) using sterile homogenizer. One loopful of suspension from each crashed nodule was then streaked across CRYEMA (Congo red yeast-extract mannitol agar) medium and incubated at $28^{\circ} \mathrm{C}$ for 3 to 7 days according to Vincent (1970). After growth, a single colony was re-streaked across CRYEMA medium repeatedly to get the single colony. The selected pure single colony of rhizobia were then inoculated on YEM (Yeast Extract Mannitol) liquid media and kept at $28^{\circ} \mathrm{C}$ with
$90 \mathrm{rpm}$ at shaking incubator for overnight. The regular shaped, uncontaminated single colonies of different nodules were collected and labeled as rhizobial isolates. Finally, each rhizobial isolate was stored at $4^{\circ} \mathrm{C}$ on agar slant and at $-80^{\circ} \mathrm{C}$ in $50 \%$ glycerol for further studies.

\section{Nodulation test at controlled condition by isolated rhizobial strain}

The viable soybean seeds were sterilized with $70 \%$ ethanol for 45 seconds and then washed gently with $2 \%$ $\mathrm{NaOCl}$ for 5 minutes. Later, the seeds were rinsed with sterile $\mathrm{dH}_{2} \mathrm{O}$ for six times and kept submerged under sterile $\mathrm{dH}_{2} \mathrm{O}$ for overnight to moisten the seeds. The moistened seeds were transferred on $1 \%$ water agar for germination. After 2 to 4 days, the germinated seeds were transferred to agar slants of $100 \mathrm{~mL}$ test tubes and cultivated in controlled condition. Overnight grown pure broth culture of each rhizobial strain was used to inoculate ( $1 \mathrm{~mL} /$ plant $) 7$ to 10 days old soybean plant aseptically. The inoculated plants were grown in the glass house at $28^{\circ} \mathrm{C}$ with 16 hours day-light and 8 hours dark photoperiod for six weeks and routinely nitrogen free Fåhreus medium (Fåhreus, 1957) was supplied to the plants. The agar slants were wrapped with aluminum foil to keep the root in dark. Three uninoculated plants were grown at the same time as negative controls and as a positive control a previously studied strain of rhizobia, $J_{11}$ (Anwar et al., 2010), was also inoculated to a plant to confirm the nodulation condition and compare the new results of this study.

\section{Biochemical test}

\section{Acid-alkali production by isolated rhizobial strains}

To know the acidic or alkaline nature of the isolated rhizobial strains, overnight growth culture $(1 \mu \mathrm{L})$ of each isolate was inoculated on YEMA plates containing $10 \%$ Bromothymol Blue (BTB) (v/v) and then incubated at $28^{\circ} \mathrm{C}$ for 3 to 7 days.

\section{Survival capacity of isolated rhizobial strains on acidic and alkaline condition}

The YEMA medium with four different $\mathrm{pH}$ were prepared, where two of them were acidic $(\mathrm{pH} 4.0$ and $\mathrm{pH} 5.0)$ and other two were basic $(\mathrm{pH} 9.0$ and $\mathrm{pH} 10)$. The overnight culture of each isolate $(1 \mu \mathrm{L})$ was inoculated on the different $\mathrm{pH}$ maintained medium and incubated at $28^{\circ} \mathrm{C}$ for 3 to 7 days.

\section{Salt (NaCl) tolerance test of the isolated rhizobia}

To know the salt tolerance of isolated strains, different 


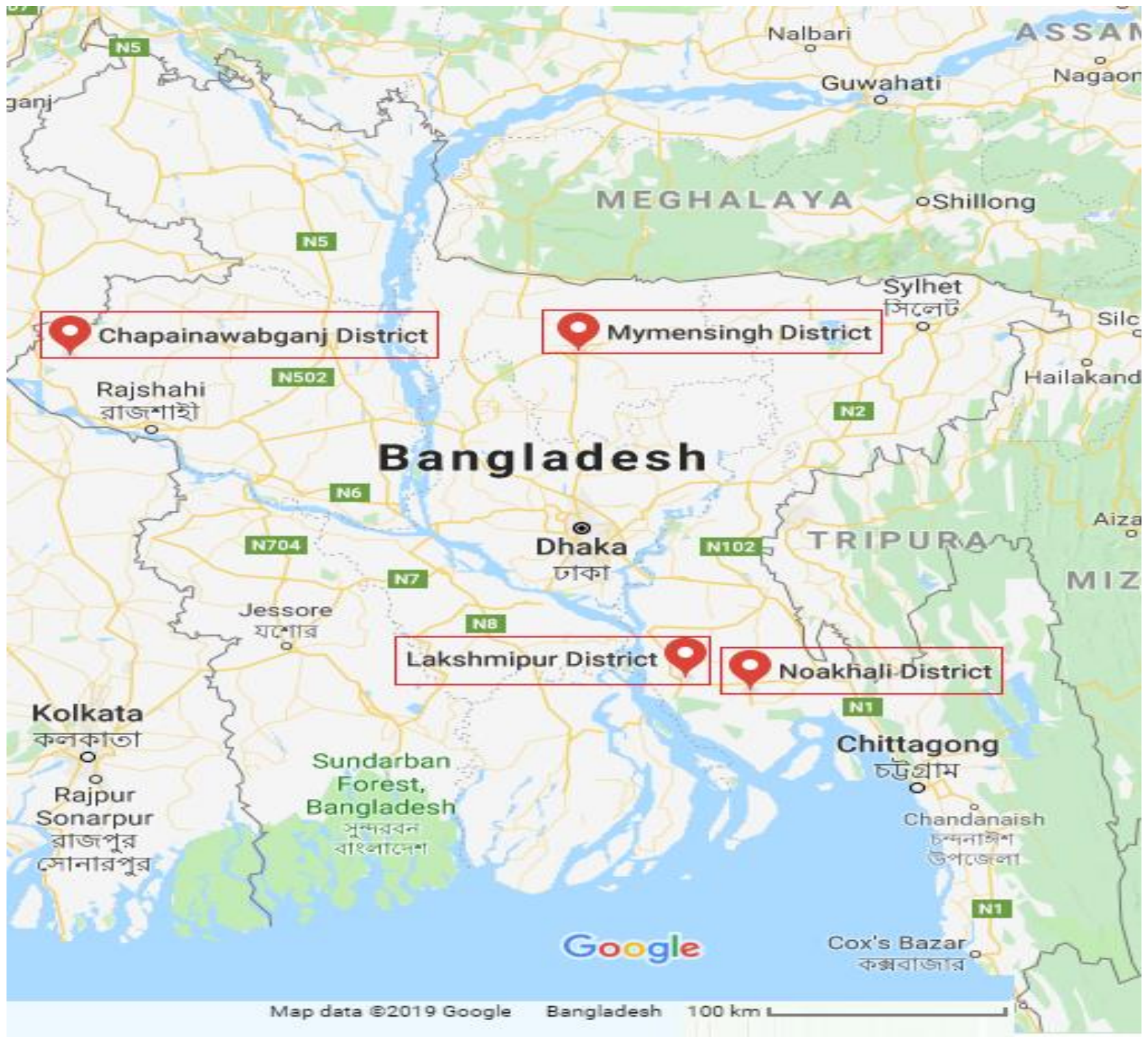

Figure 1. Map of Bangladesh: Four pins indicated the locations of nodule collection. (Photo curtsy: www.google.com.bd/maps).

levels of salt (sodium chloride: $0.5,1,2,3,4$ and $5 \%$ ) were added in YEMA (w/v). Then, pure $1 \mu \mathrm{L}$ of overnight culture of each isolate was inoculated on the salt containing media and incubated at $28^{\circ} \mathrm{C}$ for 3 to 7 days.

\section{Temperature tolerance test of the isolated rhizobia}

The temperature tolerance of isolated rhizobial strains were evaluated on YEMA medium by incubating at different temperature. One $\mu \mathrm{L}$ of overnight growth culture of each isolate was pipetted on the YEMA plates and incubated at $4{ }^{\circ} \mathrm{C}$ in refrigerator and $37,42,45,47$ and $50^{\circ} \mathrm{C}$ in dry incubator for 3 to 7 days.

\section{Symbiotic efficiency isolated rhizobia strains at potted soil at field conditions}

Soybean seeds were sunk into water overnight for better germination before sowing in potted soil. Viable moistened seeds were sowed in pots (4 seeds per pot) and cultivated properly. Each pot was prepared with $2 \mathrm{~kg}$ soil and different fertilizers like Triple super phosphate, Muriate of 
potash, Zypsum, Zinc sulphate and boric acid were used following fertilizer recommendation guide (Hassan et al., 2012). Different treatments of rhizobia were prepared with overnight grown pure culture of each rhizobial strain, recommended dose of urea solution, a previously studied strain $J_{11}$ (Anwar, 2010) as a positive control and negative control (no fertilizer, no nitrogenous fertilizer). Each rhizobial treatment $\left(2 \mathrm{~mL}\right.$ culture plant $\left.{ }^{-1}\right)$ was implied to 5 replications of 10 days aged plants. Soybean plants were cultivated in the natural condition for 6 weeks and harvested. Nodules were collected and counted properly, and then the harvested plants and nodules were dried at $60^{\circ} \mathrm{C}$ for 72 hours and data were recorded.

\section{Data collection and Statistical analysis}

The nodule numbers, nodule dry weight, and plants dry weight were collected carefully and analyzed with the program MSTAT-C developed by Russel (1986). Analysis of variance (ANOVA) for all recorded parameters was performed by F-test. The significance of the differences among the treatment means were evaluated by the least significance difference (LSD) test. After harvesting the plants and nodules, the means and standard errors of nodule numbers and plants' dry weight were analyzed by SPSS program (Version 20.0) with 5\% level of significance. The Duncan's Multiple Range Test (DMRT) (Gomez and Gomez, 1984) was performed for comparing the mean values of the different characters.

\section{RESULTS}

\section{Nodulation test}

Nodulation test is an important test to confirm the host specificity of rhizobia. Although 25 rhizobial strains were isolated from soybean root nodules, only 14 strains (SB17, SB-20, SB-22, SB-24, SB-27, SB-28, SB-34, SB-35, SB-37, SB-40, SB-42, SB-46, SB-212 and SB-452) were able to induce nodule with soybean root at laboratory conditions along with positive control $J_{11}$ but none of the negative control showed any nodule with plants' root. The nodules number varied from 10 to 25 per plant and plants dry mass varied from 270 to $530 \mathrm{mg}$, where the negative control yielded only $140 \mathrm{mg}$ (Table 1 and Figure 2).

\section{Morphological features of nodule forming rhizobial strains}

Among 25 isolated rhizobial strains, 14 soybean nodulating strains were selected and characterized (viz., SB-17, SB-20, SB-22, SB-24, SB-27, SB-28, SB-34, SB35, SB-37, SB-40, SB-42, SB-46, SB-212 and SB-452).
The isolated rhizobial strains showed different morphological features. Based on their growth time, they were categorized into three groups, seven strains of them were slow growers exposed average single colony size 1.17 to $2.00 \mathrm{~mm}$ in diameter after seven days; four strains were moderate to slow growers showed 2.00 to $2.33 \mathrm{~mm}$ colony after five days; and three strains were fast growers exposed 3.67 to $4.00 \mathrm{~mm}$ colony after three days. All single colonies of the strains were circular and convex in shape. The majority strains (64.29\%) exhibited creamy color, $21.43 \%$ strains were watery transparent and $14.29 \%$ strains were milky in color on CRYEMA plates (Table 2, Figure 3).

\section{Biochemical tests}

Most of the strains (12 out of 14) were alkali producers; showed blue color on 10\% BTB containing YEMA plates. Only two strains SB-42 and SB-452 were acid producers and exposed yellow color in the same test (Table 3).

Isolated rhizobial strains were capable to grow at alkaline $\mathrm{pH}$ (9.0 to 10.0) conditions except for the strain SB-46. Most of the strains (10 of 14) could survive at pH 5.0 (Table 3). Only two acid producing strains SB-42 and SB-452 were survived at the $\mathrm{pH}$ 4.0. All collected strains tolerated $0.5 \%$ salt but five strains of them showed poor growth at $1.0 \%$ and became inhibited at $2.0 \% \mathrm{NaCl}$. Nonetheless, about $57.14 \%$ strains (8 of 14 ) tolerated up to $3.0 \%$ salt and only the strain SB-452 retained its growth up to $4.0 \%$ and none of them sustained at $5.0 \% \mathrm{NaCl}$ (Table 4). In laboratory, the conditions rhizobia grow well on YEMA medium at $28^{\circ} \mathrm{C}$ but all studied strains were availed to grow at $37^{\circ} \mathrm{C}$. However, at least five strains (SB20, SB-22, SB-34, SB-40 and SB-42) could tolerate $42^{\circ} \mathrm{C}$ and the strains SB-34, SB-42, SB-212 and SB-452 retained their poor growth up to $45^{\circ} \mathrm{C}$ and none could tolerate at $47^{\circ} \mathrm{C}$. In addition, $4^{\circ} \mathrm{C}$ inhibited the growth of all rhizobial strains used in present study (Table 4).

\section{The effect of rhizobial treatments on growth of soybean plants}

The soybean plants were harvested after six weeks of sowing. The nodule number, dry mass, and plant dry weight were counted and analyzed (Table 5).

\section{Nodule number}

The rhizobial strains induced nodules with the root of soybean plants with a significant variation. The strains of SB-27 and SB-28 produced the highest nodule number $(60$ nodules per plant). The following numbers of nodules were produced by significantly same strains SB-24 SB-34, SB- 

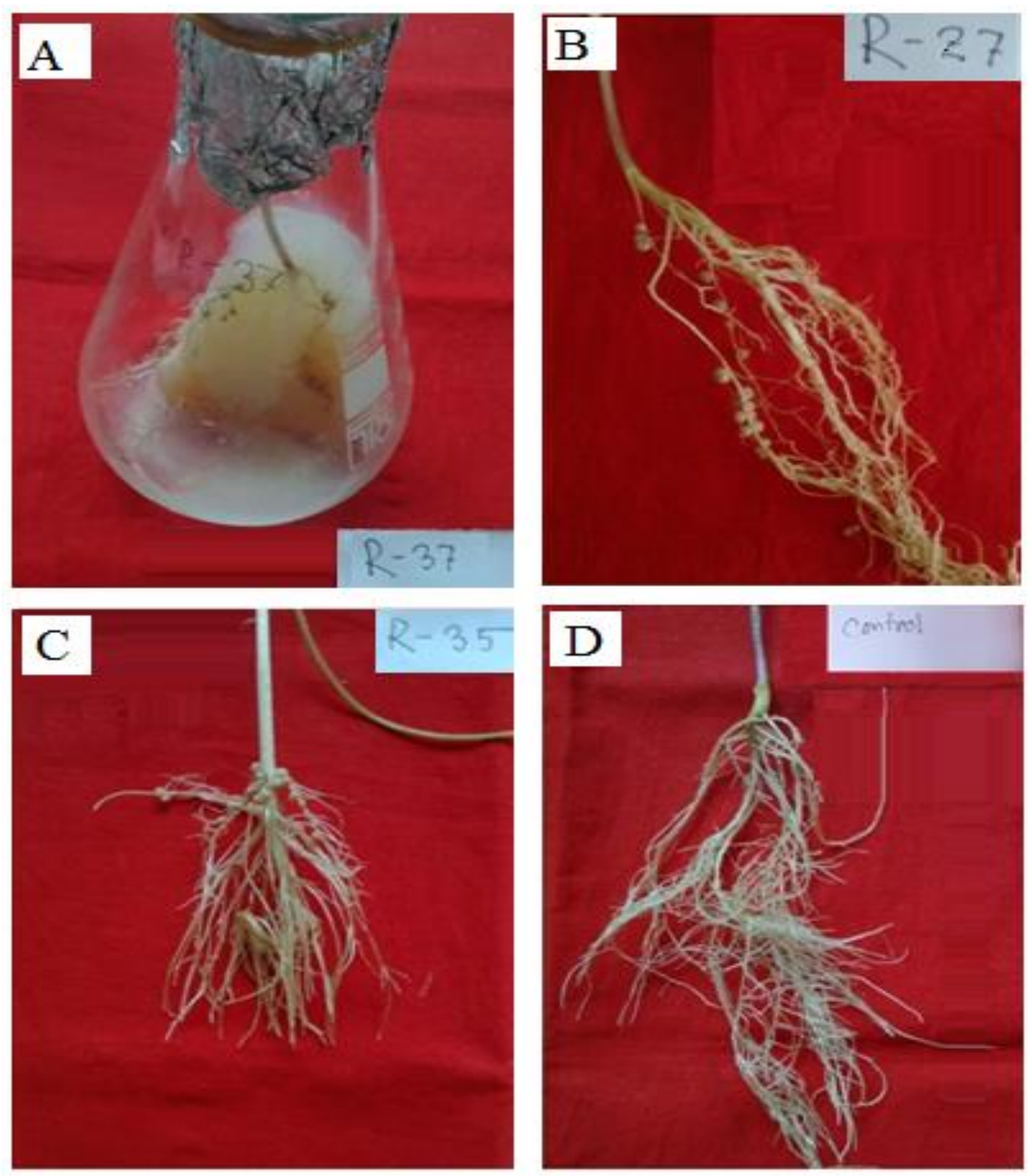

Figure 2. Re-nodulation test of rhizobial strains: Picture A,B,C represented three re-nodulated plants which were treated with overnight culture of rhizobia and $D$ represented a negatively controlled plant which was not treated with rhizobia

35 and SB-40 (43, 43, 42 and 43 nodules per plant respectively) which were followed by positive control $J_{11}$. Nevertheless, the negative control yielded the least nodule number (10 nodules per plant).

\section{Nodule dry matter weight}

The nodule dry mass was produced by different treatments ranged between $102.0 \mathrm{mg}$ and $376.0 \mathrm{mg}$ per plant. Like nodule number, the maximum nodule dry matter weight was found in the strain SB-28 $(376.0 \mathrm{mg} /$ plant $)$ and statistically similar result was produced by the strains SB37 (338.0 mg/plant), SB-27 (324.0 mg/plant), SB-35 (298.0 $\mathrm{mg} /$ plant $)$ and SB-24 (288.0 mg/plant). The control treatment yielded the minimum dry weight of nodule (102 $\mathrm{mg} /$ plant).

\section{Plant dry mass}

The different treatments of rhizobial strains had significant 
Table 1. Colony morphology of the isolated soybean rhizobia.

\begin{tabular}{lccl}
\hline Strainname & Time for single colony formation & Colonysize $(\mathbf{m m})$ & Color onCRYEMA \\
\hline SB-17 & 5 Day & 2.00 & Creamy \\
SB-20 & 3 Day & 3.67 & Transparent \\
SB-22 & 7 Day & 1.17 & Creamy \\
SB-24 & 7 Day & 2.00 & Transparent \\
SB-27 & 7 Day & 2.00 & Creamy \\
SB-28 & 7 Day & 1.67 & Creamy \\
SB-34 & 5 Day & 2.00 & Creamy \\
SB-35 & 7 Day & 1.67 & Creamy \\
SB-37 & 7 Day & 1.67 & Creamy \\
SB-40 & 7 Day & 2.00 & Creamy \\
SB-42 & 5 Day & 2.33 & Milky \\
SB-46 & 5 Day & 2.00 & Creamy \\
SB-212 & 3 Day & 4.00 & Transparent \\
SB-452 & 3 Day & 3.67 & Milky \\
Mean & & 2.28 & \\
Standard Error & & 0.23 & \\
\hline
\end{tabular}

$5 \%$ Level (SPSS Statistics 20).

Table 2. The profile of in vitro nodulation of soybean rhizobia.

\begin{tabular}{lccc}
\hline No. & Strain No. & Nodule numbers & Plant Dry mass $(\mathbf{m g})$ \\
\hline SB-17 & SB-17 & 10 & 270 \\
SB-20 & SB-20 & 25 & 470 \\
SB-22 & SB-22 & 12 & 340 \\
SB-24 & SB-24 & 14 & 390 \\
SB-27 & SB-27 & 21 & 310 \\
SB-28 & SB-28 & 15 & 260 \\
SB-34 & SB-34 & 22 & 350 \\
SB-35 & SB-35 & 20 & 250 \\
SB-37 & SB-37 & 15 & 440 \\
SB-40 & SB-40 & 18 & 320 \\
SB-42 & SB-42 & 15 & 290 \\
SB-46 & SB-46 & 23 & 350 \\
SB-212 & SB-212 & 21 & 520 \\
SB-452 & SB-452 & 16 & 380 \\
J11 (Positive Control) & & 20 & 530 \\
Negative Control * & & 0 & 140 \\
Mean & & 6.69 & 350.63 \\
Standard Error & & 1.53 & 25.91 \\
\hline
\end{tabular}

$5 \%$ Level (SPSS Statistics 20).

influence on dry matter yield of soybean plants. The highest yield ( $4676.0 \mathrm{mg} /$ plant) was produced by the strain SB-212 which was significantly similar with strains SB-28 (4542.0 mg/plant), SB-27 (4446.0 mg/plant) and SB-35 (4212.0 $\mathrm{mg} /$ plant). The control yielded the lowest plant growth $(2334.0 \mathrm{mg} / \mathrm{plant})$ which was followed by the treatments of urea and positive control $\mathrm{J}_{11}$.

\section{DISCUSSION}

Present study found a slow-growing strain SB-22 exposed the minimum (average $1.17 \mathrm{~mm}$ ) single colony with creamy color after 7 days but the fast-growing strain SB212 evolved the maximum $(4.00 \mathrm{~mm})$ watery transparent single colony after 3 days of inoculation. Colony size 

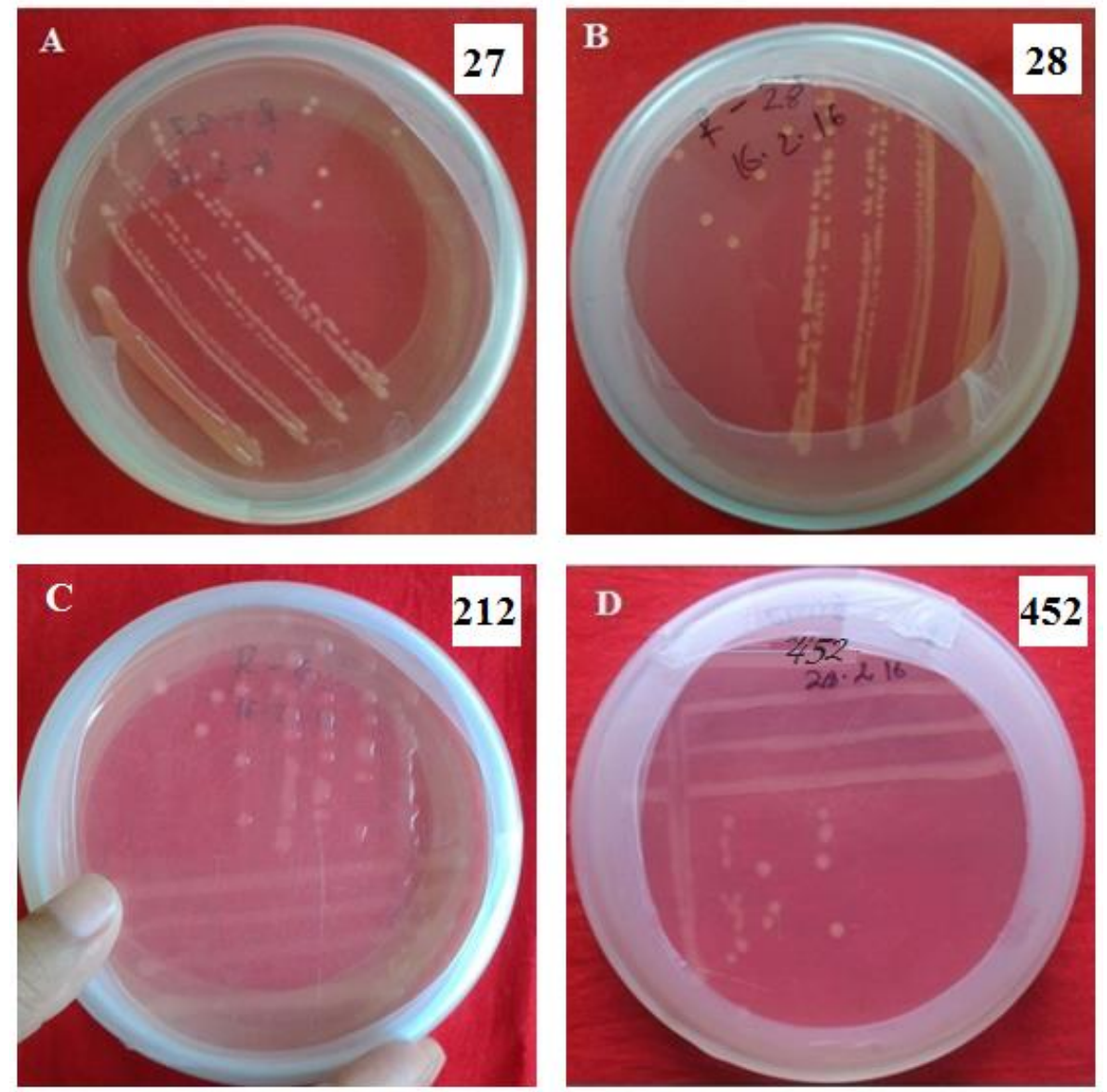

Figure 3. Colony morphology of isolated rhizobia: Plate $A$ and $B$ represented slow growing strains SB-27 and SB-28 with creamy color after seven days; C represented fast growing strain SB-212 with watery transparent color after three days; and D represented another fast growing strain SB-452 with milky color.

Table 3. Acid-alkali tolerance of soybean rhizobia and response at BTB.

\begin{tabular}{|c|c|c|c|c|c|}
\hline \multirow{2}{*}{ Strain name } & \multicolumn{4}{|c|}{$\mathrm{pH}$} & \multirow{2}{*}{ Color on BTB } \\
\hline & 4.0 & 5.0 & 9.0 & 10.0 & \\
\hline SB-17 & - & + & + & + & Blue \\
\hline SB-20 & - & \pm & ++ & ++ & Blue \\
\hline SB-22 & - & \pm & + & + & Blue \\
\hline SB-24 & - & + & + & + & Blue \\
\hline SB-27 & - & - & + & + & Blue \\
\hline SB-28 & - & - & + & + & Blue \\
\hline SB-34 & - & - & + & + & Blue \\
\hline SB-35 & - & - & + & + & Blue \\
\hline SB-37 & - & + & + & + & Blue \\
\hline SB-40 & - & - & + & + & Blue \\
\hline SB-42 & + & ++ & ++ & + & Yellow \\
\hline SB-46 & - & + & \pm & - & Blue \\
\hline SB-212 & - & \pm & ++ & ++ & Blue \\
\hline SB-452 & + & + & + & + & Yellow \\
\hline
\end{tabular}

[Note: ' \pm ' indicated poor growth, '+' indicated normal growth, '++' indicated over growth and '-' indicated no growth]. 
Table 4. Salt and temperature tolerance profiles of soybean rhizobia.

\begin{tabular}{|c|c|c|c|c|c|c|c|c|c|c|c|}
\hline \multirow{2}{*}{ Strain name } & \multicolumn{6}{|c|}{ Salt (NaCl) } & \multicolumn{5}{|c|}{ Temperature } \\
\hline & $0.5 \%$ & $1 \%$ & $2 \%$ & $3 \%$ & $4 \%$ & $5 \%$ & $4^{\circ} \mathrm{C}$ & $37^{\circ} \mathrm{C}$ & $42^{\circ} \mathrm{C}$ & $45^{\circ} \mathrm{C}$ & $47^{\circ} \mathrm{C}$ \\
\hline SB-17 & + & + & \pm & - & - & - & - & + & - & - & - \\
\hline SB-20 & ++ & ++ & + & + & - & - & - & + & + & - & - \\
\hline SB-22 & + & + & + & \pm & - & - & - & + & + & - & - \\
\hline SB-24 & + & \pm & - & - & - & - & - & + & - & - & - \\
\hline SB-27 & + & \pm & - & - & - & - & - & + & - & - & - \\
\hline SB-28 & + & \pm & - & - & - & - & - & + & - & - & - \\
\hline SB-34 & + & + & \pm & - & - & - & - & + & + & \pm & - \\
\hline SB-35 & + & \pm & - & - & - & - & - & + & - & - & - \\
\hline SB-37 & + & \pm & - & - & - & - & - & + & - & - & - \\
\hline SB-40 & + & + & + & + & - & - & - & + & + & - & - \\
\hline SB-42 & + & + & + & - & - & - & - & + & + & \pm & - \\
\hline SB-46 & + & + & + & \pm & - & - & - & + & - & - & - \\
\hline SB-212 & ++ & ++ & ++ & + & - & - & - & + & + & \pm & - \\
\hline SB-452 & ++ & ++ & ++ & + & + & - & - & + & + & \pm & - \\
\hline
\end{tabular}

[Note: ' \pm ' indicated poor growth, ' + ' indicated normal growth, '++' indicated over growth and ' - ' indicated no growth].

Table 5. Statistical analysis of the data of rhizobial strains and soybean plants.

\begin{tabular}{|c|c|c|c|}
\hline Strains & Average nodule No./plant & Nodule dry mass/plant (mg) & Plant dry mass/plant (mg) \\
\hline SB-17 & $29.2^{\text {cd }}$ & $256.0^{\text {def }}$ & $3514.0^{\mathrm{d}}$ \\
\hline SB-22 & $27.2^{\mathrm{cd}}$ & $206.0^{\text {fg }}$ & $3480.0^{\mathrm{d}}$ \\
\hline SB-24 & $43.2^{\mathrm{b}}$ & $288.0^{\text {bcde }}$ & $4130.0^{c}$ \\
\hline SB-27 & $60.6^{\mathrm{a}}$ & $324.0^{\mathrm{bc}}$ & $4446.0^{\mathrm{abc}}$ \\
\hline SB-28 & $60.6^{a}$ & $376.0^{\mathrm{a}}$ & $4542.0^{\mathrm{ab}}$ \\
\hline SB-34 & $42.8^{\mathrm{b}}$ & $248.0^{\text {def }}$ & $3318.0^{\mathrm{d}}$ \\
\hline SB-35 & $41.6^{\mathrm{b}}$ & $298.0^{\mathrm{bcd}}$ & $4212.0^{\mathrm{bc}}$ \\
\hline SB-37 & $31.0^{\mathrm{c}}$ & $338.0^{\mathrm{ab}}$ & $3530.0^{d}$ \\
\hline SB-40 & $43.0^{\mathrm{b}}$ & $238.0^{\text {ef }}$ & $3514.0^{\mathrm{d}}$ \\
\hline SB-42 & $16.4^{\text {ef }}$ & $234.0^{\text {ef }}$ & $3398.0^{d}$ \\
\hline SB-46 & $14.4^{\text {ef }}$ & $136.0^{\text {hi }}$ & $2336.0^{\mathrm{e}}$ \\
\hline SB-20 & $24.0^{\mathrm{d}}$ & $238.0^{\text {ef }}$ & $3424.0^{\mathrm{d}}$ \\
\hline SB-212 & $31.6^{c}$ & $272.0^{\text {cde }}$ & $4676.0^{\mathrm{a}}$ \\
\hline SB-452 & $17.0^{\mathrm{e}}$ & $164.0^{\mathrm{gh}}$ & $3484.0^{\mathrm{d}}$ \\
\hline $\mathrm{J}_{11}$ (Positive Con.) & $43.2^{\mathrm{b}}$ & $172.0^{\mathrm{gh}}$ & $2344.0^{\mathrm{e}}$ \\
\hline Urea & $25.2^{\mathrm{cd}}$ & $108.0^{i}$ & $2462.0^{\mathrm{e}}$ \\
\hline Negative Control & $10.0^{f}$ & $102.0^{\mathrm{i}}$ & $2334.0^{\mathrm{e}}$ \\
\hline Standard Error & 1.698 & 13.00 & 95.51 \\
\hline LSD 0.01 & 6.363 & 48.71 & 357.9 \\
\hline Level of significant & $* *$ & $\star \star *$ & $\star *$ \\
\hline
\end{tabular}

LSD $=$ Least Significant Difference, ${ }^{* *}=$ Statistically significant.

depends on the generation time of rhizobia and their mucous production ability. Thus, present study got the maximum colony size from the first growing rhizobia. Similar results were also observed by Ansari and Rao (2014) and found white opaque colonies after 7 to 10 days from slow growing rhizobial strains; pink colonies after seven days from moderate slow growing strains and fast growing strains with 4 to $8 \mathrm{~mm}$ watery translucent colonies after 2 to 3 days. On the basis of growth, rhizobia were categorized into two groups: first and slow grower but current study got three groups from soybean nodules from Bangladesh. Similar results also observed by Vincent (1974). Singh et al. (2013) mentioned that the mean generation time of fast-growing rhizobia is between 2 and 4 hours, and 6 hours for slow growing rhizobia.

Although rhizobia grow well on YEMA medium at $28^{\circ} \mathrm{C}$ but all studied strains were availed to grow at $37^{\circ} \mathrm{C}$ and five strains (SB-20, SB-22, SB-34, SB-40, and SB-42) 
could tolerate $42^{\circ} \mathrm{C}$. Even the strains SB-34, SB-42, SB212 , and SB-452 retained their poor growth up to $45^{\circ} \mathrm{C}$ and none could tolerate at $47^{\circ} \mathrm{C}$. In addition, $4^{\circ} \mathrm{C}$ inhibited the growth of all the rhizobial strains of the study. Ledgard and Steele (1992) and Berrada et al. (2012) also reported that rhizobial strains grew normally between 20 and $37^{\circ} \mathrm{C}$ temperature, some of them tolerated from 35 to $40^{\circ} \mathrm{C}$ even the highest $50^{\circ} \mathrm{C}$ but not over $55^{\circ} \mathrm{C}$. This may be happened due to the influence of local environment because generally bacteria can cope up with their ecosystem and become habituated with various environmental responses. However, some strains from current study also tolerated temperature between $40^{\circ} \mathrm{C}$ and $45^{\circ} \mathrm{C}$, which might be for their increased expression of some heat shock proteins, as Michiels et al. (1994) detected 14 heat shock proteins in rhizobial strains, grew within 40 to $45^{\circ} \mathrm{C}$. The stress tolerance of rhizobia may depend on indigenous atmosphere because Abo-Aba et al. (2015) isolated three $R$. leguminosarum strains from drought-prone areas from Saudi Arabia those were competent to grow at a wide range of temperature from 30 to $60^{\circ} \mathrm{C}$.

Bromothymol blue (BTB) functioned as a weak acid solution and changed its color after reacting with bacterial acidic or basic mucous. Present study identified that the fast growing strain SB-42 and SB-452 were acid producers that is why they exposed yellow color and the rest strains were alkali producers and showed blue color at BTB. Similar result was observed by Sharma et al. (2010) and reported that acid producing rhizobia exposed yellow color and alkaline mucous exposed blue color. Dowdle and Bohlool (1985) and Chen et al. (2000) also observed that the fast growing acid producing strains showed yellow and alkali producing strains showed blue color at BTB. Consequently, the fast growing and acid producing strains SB-42 and SB-452 were competent to grow at acidic $\mathrm{pH}$ 4.0 and 5.0. Generally, rhizobia can tolerate a wide range of $\mathrm{pH}$, for instance, Fujihara and Yoneyama (1993), Correa and Barneix (1997) and Reza et al. (2001) reported that Mesorhizobiaum $s p$. and Rhizobium fredii tolerated $\mathrm{pH}$ from 4.0 to 10.0. On the other hand, the alkali producing strains tolerated $\mathrm{pH} 9.0$ and 10.0. It is possible because rhizobia have the capacity of tolerance a wide range of $\mathrm{pH}$, from 4.0 to 10.0 (Correa and Barneix,1997; Sharma et al. 2010; Rahman et al., 2018).

Normally, rhizobia have both of resistance and sensitivity at salt, for instance, Abo-Aba et al. (2015) described that Rhizobium leguminosarum strains tolerated salt ranged from 0.5 to $4 \% \mathrm{NaCl}$. Moreover, the fast growing rhizobia were more salt tolerant than slow growing Bradyrhizobia (Hua et al., 1982; Zahran, 1999). Several genes have been identified in rhizobia which produce response to adapt salinity (Wei, 2004).

The pot experiment conducted at field conditions showed that the strains SB-27 and SB-28 produced almost double growth of soybean plants over urea and control treatment. However, the strain SB-212 yielded the maximum plant growth according to dry mass though its nodule number and nodule mass were not the highest. Similar results also observed by Chibeba et al. (2017), Habibi et al. (2017) and Kapembwa et al. (2016). In the present study, the nodule dry mass of each plant was not evenly proportioned with their respective nodule number because the nodule size was not similar. This is a very normal phenomenon of rhizobia because it can form different types and size of nodules on legume root system (Ngakou et al., 2009). Similarly, Anwar et al. (2010) observed a large variation by the treatments of different rhizobial strains on soybean plants. Generally, rhizobia are considered as beneficial bacteria which enhance growth and yield of respective host plant. However, the present study found a few numbers of strains functioned efficiently and most of the strains had diverse efficiency. This may happen due to selfish behavior of strains. Ratcliff et al. (2008) explained that there are some selfish rhizobia which can produce nodules and take a sufficient amount nutrient from the host but do not give back better nitrogen to their host and thus, negatively affect the plants growth.

\section{Conclusion}

Locally adapted soybean nodulating rhizobial strains had been isolated and characterized from different districts of Bangladesh. Diversity was observed among most of the rhizobial strains based on different characters including colony morphology, growth time; acid-alkali resistance salt and temperature tolerance. Importantly, three strains (SB27, SB-28 and SB-212) showed the highest symbiotic potentiality and consequently yielded better plant growth than other strains/treatments. This study increased further collection of effective rhizobial strains for inoculants production to enhance soybean growth. The study suggests that the inoculation with locally well adapted strains could be a better avenue for increasing soybean growth and yield in Bangladesh. Further field trails are needed to confirm the findings in this research.

\section{CONFLICTS OF INTEREST}

We do not have any conflicts of interest.

\section{ACKNOWLEDGMENT}

We eagerly acknowledge to Dr. K.M. Nasiruddin for his valuable instruction and Md. Kamruzaman for reading our manuscript. We are also grateful to the Ministry of Science and Technology, Bangladesh (no.39.009.002.01.00.057. 2015-2016/922/BS168) and the authority of Bangladesh Institute of Nuclear Agriculture for their support to conduct this research. 


\section{REFERENCES}

Abo-Aba, S. E. M., Mutwakil, M. Z., \& Al-Ahmadi, T. M. (2015). Isolation and molecular characterization of heat and salt tolerance rhizobia isolated from Saudi Arabia. Journal of American Science, 11, 150-156.

Ansari, P. G., \& Rao, D. L. N. (2014). Differentiating Indigenous Soybean Bradyrhizobium and Rhizobium spp. of Indian Soils. Indian journal of microbiology, 54(2), 190-195.

Anwar, A. H. M. N., Podder, A. K., Hasem, M. A., Bala, P., \& Islam, M. A. (2010). Effect of Bradyrhizobium inoculants on the growth and yield of soybean varieties PB-1 and G-2. Journal of Soil Nature, 4(1), 39-48.

Berrada, H., \& Fikri-Benbrahim, K. (2014). Taxonomy of the rhizobia: current perspectives. British Microbiology Research Journal, 4(6), 616-639.

Berrada, H., Nouioui, I., Houssaini, M. I., Ghachtouli, N. E., Gtari, M., \& Benbrahim, K. F. (2012). Phenotypic and genotypic characterizations of rhizobia isolated from root nodules of multiple legume species native of $\mathrm{Fez}$, Morocco. African Journal of Microbiology Research, 6(25), 5314-5324.

Chen, L. S., Figueredo, A., Pedrosa, F. O., \& Hungria, M. (2000). Genetic characterization of soybean rhizobia in Paraguay. Applied and environmental microbiology, 66(11), 5099-5103.

Chibeba, A. M., Kyei-Boahen, S., de Fátima Guimarães, M., Nogueira, M. A., \& Hungria, M. (2017). Isolation, characterization and selection of indigenous Bradyrhizobium strains with outstanding symbiotic performance to increase soybean yields in Mozambique. Agriculture, Ecosystems \& Environment, 246, 291-305.

Correa, O. S., \& Barneix, A. J. (1997). Cellular mechanisms of $\mathrm{pH}$ tolerance in Rhizobium loti. World Journal of Microbiology and Biotechnology, 13(2), 153-157.

Dowdle, S. F., \& Bohlool, B. B. (1985). Predominance of fastgrowing Rhizobium japonicum in a soybean field in the People's Republic of China. Applied and Environmental Microbiology, 50(5), 1171-1176.

Fåhreus, G. (1957). The infection of clover root hairs by nodule bacteria studied by a simple glass slide technique. Microbiology, 16(2), 374-381.

Fujihara, S., \& Yoneyama, T. (1993). Effects of pH and osmotic stress on cellular polyamine contents in the soybean rhizobia Rhizobium fredii P220 and Bradyrhizobium japonicum A1017. Applied and Environmental Microbiology, 59(4), 1104-1109.

Gomez, K. A., \& Gomez, A. A. (1984). Duncan's multiple range tests.Statistical procedure for agricultural research. J. Wiley and Sons (Ed). (A Wiley interscience publication). Pp. 205207.

Goormachtig, S., Capoen, W., \& Holsters, M. (2004). Rhizobium infection: lessons from the versatile nodulation behaviour of water-tolerant legumes. Trends in Plant Science, 9(11), 518522.

Habibi, S., Ghani Ayubi, A., Ohkama-Ohtsu, N., Sekimoto, H., \& Yokoyama, T. (2017). Genetic characterization of soybean rhizobia isolated from different ecological zones in NorthEastern Afghanistan. Microbes and Environments, 32(1), 7179.

Hassan, A. A., Jahiruddin, M., Noor, S., Sarker, M. J. U., Shah, A.L., Khan, M. M. K., Bokhtiar, S. M., Quddus, M. A., Hasan, M. N., Razia, M. S., and Sattar, M. A. (2012). Fertilizer Recommendation Guide. Bangladesh Agricultural Research Council, Dhaka. p. 274
Herridge, D. F., Peoples, M. B., \& Boddey, R. M. (2008). Global inputs of biological nitrogen fixation in agricultural systems. Plant and Soil, 311(1-2), 1-18.

Hua, S. S. T., Tsai, V. Y., Lichens, G. M., \& Noma, A. T. (1982). Accumulation of amino acids in Rhizobium sp. strain WR1001 in response to sodium chloride salinity. Applied and Environmental Microbiology, 44(1), 135-140.

Jordan, D. C. (1984). Family III Rhizobiaceae. In: Bergey's Manual of Systematic Bacteriology. N.R. Krieg and J.G. Holt (Ed). (Williams and Wilkins, Baltimore). Pp. 234-242.

Kapembwa, R., Mweetwa, A. M., Ngulube, M., \& Yengwe, J. (2016). Morphological and biochemical characterization of soybean nodulating rhizobia indigenous to Zambia. Sustainable Agriculture Research, 5(3), 84-92.

Ledgard, S. F., \& Steele, K. W. (1992). Biological nitrogen fixation in mixed legume/grass pastures. Plant and Soil, 141(1-2), 137153.

MacLean, A. M., Finan, T. M., \& Sadowsky, M. J. (2007). Genomes of the symbiotic nitrogen-fixing bacteria of legumes. Plant Physiology, 144(2), 615-622.

McNeill, A., \&Unkovich, M. (2007). The nitrogen cycle in terrestrial ecosystems. Soil Biology, 10, 37-64.

Michiels, J., Verreth, C., \& Vanderleyden, J. (1994). Effects of temperature stress on bean-nodulating Rhizobium strains. Applied and Environmental Microbiology, 60(4), 1206-1212.

Ngakou, A., Megueni, C., Ousseni, H., \& Massai, A. (2009). Study on the isolation and characterization of rhizobia strains as biofertilizer tools for growth improvement of four grain legumes in Ngaoundéré-Cameroon. International Journal of Biological and Chemical Sciences, 3(5), 1078-1089.

Rahman, M. H., Khatun, S., Ali, S. R., Yasmin, S., Kamruzzaman, M., \& Rashid, M. H. (2018). Morpho-Physiological diversity of root nodule rhizobia from Mimosa (Mimosa pudica L) and Water Mimosa (Neptunia oleracea L). Journal of Bacteriology and Mycology, 5, 1061.

Ratcliff, W. C., Kadam, S. V., \& Denison, R. F. (2008). Poly-3hydroxybutyrate (PHB) supports survival and reproduction in starving rhizobia. FEMS Microbiology Ecology, 65(3), 391-399.

Reza, S., Jørnsgård, B., Abou-Taleb, H., \& Christiansen, J. L. (2001). Tolerance of Bradyrhizobium sp. (Lupini) strains to salinity, $\mathrm{pH}, \mathrm{CaCO}_{3}$ and antibiotics. Letters in Applied Microbiology, 32(6), 379-383

Ross-lbarra, J., Morrell, P. L., \& Gaut, B. S. (2007). Plant domestication, a unique opportunity to identify the genetic basis of adaptation. Proceedings of the National Academy of Sciences, 104 (suppl 1), 8641-8648.

Russel, D. F. (1986). MSTAT-C package progamme. Crop and Soil Science Department. Michigan State University, United States of America.

Sharma, M. P., Srivastava, K., \& Sharma, S.K. (2010). Biochemical characterization and metabolic diversity of soybean rhizobia isolated from Malwa region of Central India. Plant, Soil and Environment, 56 (8), 375-383.

Singh, S. K., Jaiswal, S. K., Vaishampayan, A., \& Dhar, B. (2013). Physiological behavior and antibiotic response of soybean (Glycine max L.) nodulating rhizobia isolated from Indian soils. African Journal of Microbiology Research, 7(19), 2093-2102.

Vincent, J. M. (1970). A Manual for the Practical Study of root nodule bacteria. Oxford Publication for the International Biological Program (First edition). p.164.

Vincent, J. M. (1974). Root nodule symbiosis with Rhizobium. In: Biology of nitrogen fixation. A. Quispel (Ed). North-Holland 
Publishing Company, Amsterdam. Pp. 265-347.

Wei, W., Jiang, J., Li, X., Wang, L., \& Yang, S. S. (2004). Isolation of salt-sensitive mutants from Sinorhizobium meliloti and characterization of genes involved in salt tolerance. Letters in Applied Microbiology, 39(3), 278-283.
Zahran, H. H. (1999). Rhizobium-legume symbiosis and nitrogen fixation under severe conditions and in an arid climate. Microbiology and Molecular Biology Reviews, 63(4), 968-989. 